\title{
A note on "A mixed integer programming formulation for multi floor layout" [African Journal of Business Management 3 (2009) 616-620]
}

\author{
Krishna k. Krishnan ${ }^{1}$ and Amir Ardestani Jaafari ${ }^{2 \star}$ \\ ${ }^{1}$ Industrial and Manufacturing Engineering, Wichita State University, Wichita, Kansas, USA. \\ ${ }^{2}$ Department of Industrial Engineering, Amirkabir University of Technology, Tehran, Iran.
}

Accepted 15 July, 2010

\begin{abstract}
In the aforesaid paper, some pages are omitted reluctantly and are corrected thus. In this paper, the two-floor facility layout problem with unequal departmental areas in multi-bay environments is addressed. A mixed integer programming formulation is developed to find the optimal solution to the problem. This model determines position and number of elevators with consideration of conflicting objectives simultaneously. Objectives include to minimize material handling cost and to maximize closeness rating. A memetic algorithm (MA) is designed to solve the problem and it is compared with the corresponding genetic algorithm for large-sized test instances and with a commercial linear programming solver solution to small-sized test instances. Computational results proved the efficiency of solution procedure to the problem.
\end{abstract}

Key words: Mixed integer programming, multi floor layout, multi objective, memetic algorithm.

\section{INTRODUCTION}

One of the oldest activities done by industrial engineers is facilities planning. The term facilities planning can be divided into two parts: facility location and facility layout. The latter is one of the foremost problems of modern manufacturing systems and has three sections: layout design, material handling system design and facility system design (Tompkins et al., 2003).

Determining the most efficient arrangement of physical departments within a facility is defined as a facility layout problem (FLP). Layout problems are known to be complex and are generally NP-Hard (Enea et al., 2005). Classical approaches to layout designing problems tend to maximize the efficiency of layouts measured by the handling cost related to the interdepartmental flow and the distance among the departments. However, the actual problem involves several conflicting objectives hence requires a multi-objective formulation (Aiello et al., 2006). The common objectives to layout designing are

${ }^{*}$ Corresponding author. E-mail:
ardestanijaafari.amir@yahoo.com, ardestani.amir@aut.ac.ir. minimizing the total cost of material transportation and maximizing the total closeness rating between the two departments. In some cases, they are combined as (Meller and Gau, 1996):

$$
\min \alpha \sum_{i} \sum_{j}\left(f_{i j} c_{i j}\right) d_{i j}-(1-\alpha) \sum_{i} \sum_{j} r_{i j} x_{i j}
$$

which is the weighted coefficient of objective functions, that is, it shows the material flow between the departments, it shows the cost of moving in unit distance of material flow between the two departments, it shows the closeness ratio between the two departments and is an indicator which shows that when the departments have common boundary, it is otherwise zero. Setting the parameter $\alpha$ has been studied by Meller and Gau (1997).

Aiello et al. (2006) represented a two-stage multiobjective flexible-bay layout. Genetic Algorithm (GA) was used to find Pareto-optimal in the first stage and the selection of an optimal solution was carried out by Electre method in the second stage. These objectives considered minimization of the material handling cost, maximization 
of the satisfaction of weighted adjacency, maximization of the satisfaction of distance requests and maximization of the satisfaction of aspect ratio requests. Pierreval et al. (2003) described evolutionary approaches to the design of manufacturing systems. Chen and Sha (2005) presented a multi-objective heuristic which contained workflow, closeness rating, material-handling time and hazardous movement. Şahin and Türkbey (2008) proposed simulated annealing algorithm to find Pareto solutions for multi-objective facility layout problems including total material handling cost and closeness rating. A qualitative and quantitative multi-objective approach to facility layout was developed by Peters and Yang (1997). Peer and Sharma (2008) considered material handling and closeness relationships in multi-goal facilities layout. Konak et al. (2006) conducted a survey on multi-objective optimization using genetic algorithms and Loiola et al. (2007) provided a review paper for the quadratic assignment problem (QAP) which concerned multi-objective QAP.

In this paper, we consider both issue of multi objective and multi floor. Nowadays, when it comes to the construction of a factory in an urban area, land providing is generally insufficient and expensive. The limitation of available horizontal space creates a need to use a vertical dimension of the workshop. Then, it can be relevant to locate the facilities on several floors Drira et al. (2007).

Meller and Bozer (1997) compared approaches of multi-floor facility layout. Lee et al. (2005) used GA multifloor layout which minimized the total cost of material transportation and adjacency requirement between departments while satisfied constraints of area and aspect ratios of departments. A five-segmented chromosome represented multi-floor facility layout. Many firms are likely to consider renovating or constructing multi-floor buildings, particularly in those cases where land is limited (Bozer and Meller, 1994). Matsuzaki et al. (1999) developed a heuristic for multi-floor facility layout considering capacity of elevator. Patsiatzis et al. (2002) presented a mixed integer linear formulation for the multi-floor facility layout problem. This work was extended model of the single-floor work of Papageorgiou and Rotstein (1998).

We focus on flexible bay-structured layout. In the baystructured facility layout problems, a pre-specified rectangular floor space is first partitioned horizontally or vertically into bays and then each bay is divided into blocks with equal width but different lengths. Some typical works in bay layout are Aiello et al. (2006), Arapoglu et al. (2001), Castillo and Peters (2004), Chae and Peters (2006), Chen et al. (2002), Eklund et al. (2006), Enea et al. (2005), Garey and Johnson (1979), Konak et al. (2006), Kulturel-Konak et al. (2004), Meller (1997), Peters and Yang (1997) and Tate and Smith (1995).

In this paper, we formulate a multi floor layout considering conflicting objectives. Objectives are commonused in previous works and include to minimize material handling cost and to maximize closeness rating. Then, a memetic algorithm is developed to solve the problem.

\section{MATHEMATICAL MODEL}

\section{Sets and indices}

Set of cells in block layout graph.

\section{A. Variables}

$z_{i k}= \begin{cases}1, & \begin{array}{l}\text { If department } i \text { is assigned to } \\ \text { bay } k \text { in the first floor }\end{array} \\ 0, & \text { otherwise }\end{cases}$

$z_{i k}^{\prime}= \begin{cases}1, & \begin{array}{l}\text { If department } i \text { is assigned to } \\ \text { bay } k \text { in the second floor }\end{array} \\ 0, & \text { otherwise }\end{cases}$

$r_{i j}=\left\{\begin{array}{rrr}1 & \text { If department } i \text { is located above } \\ & \text { department } \quad j \text { in the same bay } \\ 0 & \text { otherwise }\end{array}\right.$

$\delta_{k}= \begin{cases}1, & \text { If bay } k \text { is occupied in the first floor } \\ 0, & \text { otherwise }\end{cases}$

$\delta_{k}^{\prime}= \begin{cases}1, & \text { If bay } k \text { is occupied in the second floor } \\ 0, & \text { otherwise }\end{cases}$

$G_{i}=\left\{\begin{array}{lc}1 & \text { If department } i \text { is located in the first floor } \\ 0 & \text { Otherwise }\end{array}\right.$

$y_{i j}= \begin{cases}1, & \text { If department } \mathrm{s} i \text { and } j \text { have } \\ & \text { common boundary } \\ 0, & \text { Otherwise }\end{cases}$

$w_{k}$ Width (the length in the $\mathrm{x}$-axis direction) of bay $\mathrm{i}$ in first floor; $w_{k}^{\prime}$ Width (the length in the $x$-axis direction) of bay $\mathrm{i}$ in second floor; $w_{i k}^{1}$ Width (the length in the $\mathrm{x}$-axis direction) of bay $\mathrm{i}$ in bay $\mathrm{k}$ in first floor; $w_{i k}^{2}$ Width (the length in the $x$-axis direction) of bay $i$ in bay $k$ in second floor; $l_{i}^{y}$ Height (the length in the $y$-axis direction) of department $\mathrm{i}$ in first floor; $l_{i}^{\prime y}$ Height (the length in the $\mathrm{y}$ - axis 
direction) of department $\mathrm{i}$ in second floor; $\left(o_{i}^{x}, o_{i}^{y}\right)$ Coordinates of the centroid of department $\mathrm{i}$ in first floor; $\left(o_{i}^{\prime x}, o_{i}^{\prime y}\right)$ Coordinates of the centroid of department $\mathrm{i}$ in second floor; $d_{i j}^{x}$ Distance between the centroid of departments $\mathrm{i}$ and $\mathrm{j}$ in the $\mathrm{x}$-axis direction in first floor; $d_{i j}^{\prime x}$ Distance between the centroid of departments $\mathrm{i}$ and $\mathrm{j}$ in the $\mathrm{x}$-axis direction in second floor; $d_{i j}^{y}$ Distance between the centroid of departments $i$ and $j$ in the $y$-axis direction in first floor; $d_{i j}^{\prime y}$ Distance between the centroid of departments $\mathrm{i}$ and $\mathrm{j}$ in the $\mathrm{y}$-axis direction in second floor; $h_{i k}$ Height (the length in the $y$-axis direction) of department $\mathrm{i}$ in first floor; $h_{i k}^{\prime}$ Height (the length in the $y$ axis direction) of department $\mathrm{i}$ in second floor; $\left(U p_{i}^{x}, U p_{i}^{y}\right)$ Coordinates of the northeastern corner of department $\mathrm{i}$; $\left(L o_{i}^{x}, L o_{i}^{y}\right)$ Coordinates of the southwestern corner of department i.

$s_{1}= \begin{cases}1, & \text { if the first elevatoris used } \\ 0, & \text { otherwise }\end{cases}$

$s_{2}= \begin{cases}1, & \begin{array}{c}\text { if the first elevator is located in } \\ \text { the southwest corner of facility }\end{array} \\ 0, & \begin{array}{l}\text { if the first elevator is located in } \\ \text { the northwest corner of facility }\end{array}\end{cases}$

$s_{3}= \begin{cases}1, & \begin{array}{l}\text { if the second elevator is located in } \\ \text { the southeast corner of facility }\end{array} \\ 0, & \begin{array}{l}\text { if the second elevator is located in } \\ \text { the northeast corner of facility }\end{array}\end{cases}$

\section{B. Parameters}

$n$ : Number of departments; $W$ : Width of the facility along the $x$-axis; $H$ : Width of the facility along the $y$-axis; $a_{i}$ : Area requirement of department $i ; \alpha_{i}$ : Aspect ratio of department $i ; l_{i}^{\max }$ : Maximum permissible side length of department $i ; l_{i}^{\text {min. }}$ : Maximum permissible side length of department $i: f_{i j}$ Amount of material flow between departments $i$ and $j ; c_{i j}$ : Amount of material cost between departments $i$ and $j$ if they would be in different floors in $y$-axis; $a d j_{i j}$ : Adjacency ratio between departments $i$ and $j ; H e$ : Distance between two department in z-axis; $p_{1}, p_{2}$ : Weights of objective functions.

\section{Assumptions}

i. The coordinates of the southwestern corner of the facility are $(0,0)$.

ii. In the model description, the long side of the facility is along the $x$-axis direction, and bays are assumed to be vertically arranged within the facility.

iii. If a department is assigned to a bay, then the bay must be completely filled.

iv. If the aspect ratio is specified to control departmental shapes, then $l_{i}^{\min }=\sqrt{a_{i} / \alpha_{i}}, l_{i}^{\max }=\sqrt{a_{i} \alpha_{i}}$

\section{Problem formulation}

In our paper, we extend their model with following constraints:

$W\left(2-G_{i}-G_{j}\right)+d_{i j}^{x} \geq\left(o_{i}^{x}-o_{j}^{x}\right) \quad \forall i<j$,

$W\left(2-G_{i}-G_{j}\right)+d_{i j}^{x} \geq\left(o_{j}^{x}-o_{i}^{x}\right) \quad \forall i<j$,

$L\left(2-G_{i}-G_{j}\right)+d_{i j}^{x} \geq\left(o_{i}^{x}-o_{j}^{x}\right) \quad \forall i<j$,

$L\left(2-G_{i}-G_{j}\right)+d_{i j}^{x} \geq\left(o_{j}^{x}-o_{i}^{x}\right) \quad \forall i<j$,

$W\left(2-\left(1-G_{i}\right)-\left(1-G_{j}\right)\right)+d_{i j}^{\prime x} \geq\left(o_{i}^{\prime x}-o_{j}^{\prime x}\right) \forall i<j$,

$W\left(2-\left(1-G_{i}\right)-\left(1-G_{j}\right)\right)+d_{i j}^{\prime x} \geq\left(o_{j}^{\prime x}-o_{i}^{\prime x}\right) \quad \forall i<j$,

$L\left(2-\left(1-G_{i}\right)-\left(1-G_{j}\right)\right)+d_{i j}^{\prime y} \geq\left(o_{i}^{\prime y}-o_{j}^{\prime y}\right) \quad \forall i<j$,

$L\left(2-\left(1-G_{i}\right)-\left(1-G_{j}\right)\right)+d_{i j}^{\prime y} \geq\left(o_{j}^{\prime y}-o_{i}^{\prime y}\right) \quad \forall i<j$,

Constraints (1) to (8) linearize the absolute value term in the rectilinear distance function in the first and second floor.

$\sum_{k} z_{i k}=G_{i} \quad \forall i$,

$\sum_{k} z_{i k}^{\prime}=1-G_{i} \quad \forall i$

Constraints (9) and (10) states that each department is located in a bay.

$w_{k}=\frac{1}{L} \sum_{i} z_{i k} a_{i} \quad \forall k$, 


$$
\begin{aligned}
& w_{k}^{\prime}=\frac{1}{L} \sum_{i} z_{i k}^{\prime} a_{i} \quad \forall k \\
& l_{i}^{\min } z_{i k} \leq w_{k} \leq l_{i}^{\max }+W\left(1-z_{i k}\right) \quad \forall i, k, \\
& l_{i}^{\min } z_{i k}^{\prime} \leq w_{k}^{\prime} \leq l_{i}^{\max }+W\left(1-z_{i k}^{\prime}\right) \quad \forall i, k,(14) \\
& o_{i}^{x} \leq \sum_{j \leq k} w_{j}-0.5 w_{k}+\left(W-l_{i}^{\min }\right)\left(1-z_{i k}\right) \quad \forall i, j, k \\
& o_{i}^{x} \geq \sum_{j \leq k} w_{j}-0.5 w_{k}-\left(W-l_{i}^{\min }\right)\left(1-z_{i k}\right) \forall i, j, k \\
& o_{i}^{\prime x} \leq \sum_{j \leq k} w_{j}^{\prime}-0.5 w_{k}^{\prime}+\left(W-l_{i}^{\min }\right)\left(1-z_{i k}^{\prime}\right) \quad \forall i, j, k \\
& o_{i}^{\prime x} \geq \sum_{j \leq k} w_{j}^{\prime}-0.5 w_{k}^{\prime}-\left(W-l_{i}^{\min }\right)\left(1-z_{i k}^{\prime}\right) \quad \forall i, j, k \\
& \frac{h_{i k}}{a_{i}}-\frac{h_{j k}}{a_{j}}-\max \left\{\frac{l_{i}^{\max }}{a_{i}}, \frac{l_{j}^{\max }}{a_{j}}\right\}\left(2-z_{i k}-z_{j k}\right) \leq 0 \quad \forall i, j, k \\
& \frac{h_{i k}}{a_{i}}-\frac{h_{j k}}{a_{j}}+\max \left\{\frac{l_{i}^{\max }}{a_{i}}, \frac{l_{j}^{\max }}{a_{j}}\right\}\left(2-z_{i k}-z_{j k}\right) \geq 0 \forall i, j, k \\
& \frac{h_{i k}^{\prime}}{a_{i}}-\frac{h_{j k}^{\prime}}{a_{j}}-\max \left\{\frac{l_{i}^{\max }}{a_{i}}, \frac{l_{j}^{\max }}{a_{j}}\right\}\left(2-z_{i k}^{\prime}-z_{j k}^{\prime}\right) \leq 0 \quad \forall i, j, k \\
& \frac{h_{i k}^{\prime}}{a_{i}}-\frac{h_{j k}^{\prime}}{a_{j}}+\max \left\{\frac{l_{i}^{\max }}{a_{i}}, \frac{l_{j}^{\max }}{a_{j}}\right\}\left(2-z_{i k}^{\prime}-z_{j k}^{\prime}\right) \geq 0 \quad \forall i, j, k \\
& \sum_{i} h_{i k}=\mathrm{H} \delta_{k} \quad \forall i, k \\
& \sum_{i} h_{i k}^{\prime}=\mathrm{H} \delta_{k}^{\prime} \quad \forall i, k \\
& l_{i}^{\min } z_{i k} \leq h_{i k} \leq l_{i}^{\max } z_{i k} \quad \forall i, k \\
& l_{i}^{\min } z_{i k}^{\prime} \leq h_{i k}^{\prime} \leq l_{i}^{\max } z_{i k}^{\prime} \quad \forall i, k \\
& \sum_{k} h_{i k}=l_{i}^{y} \quad \forall i, k \\
& \sum_{k} h_{i k}^{\prime}=l_{i}^{\prime y} \quad \forall i, k
\end{aligned}
$$$$
o_{i}^{y}-0.5 l_{i}^{y} \geq o_{j}^{y}+0.5 l_{j}^{y}-H\left(1-r_{i j}\right) \quad \forall i \neq j,
$$$$
o_{i}^{\prime y}-0.5 l_{i}^{\prime y} \geq o_{j}^{\prime y}+0.5 l_{j}^{\prime y}-H\left(1-r_{i j}\right) \quad \forall i \neq j,
$$$$
r_{i j}+r_{j i} \geq z_{i k}^{\prime}+z_{j k}^{\prime}-1 \quad \forall i<j, k
$$$$
0.5 l_{i}^{y} \leq o_{i}^{y} \leq H-0.5 l_{i}^{y} \quad \forall i,
$$$$
0.5 l_{i}^{\prime y} \leq o_{i}^{\prime y} \leq H-0.5 l_{i}^{\prime y} \quad \forall i
$$

Constraints (11) to (33) state restrictions of length and width of each department and determine coordination of each department.

$$
\begin{aligned}
& w_{i}^{1}=\sum_{k} z_{i k} w_{k} \quad \forall i, k \\
& w_{i}^{2}=\sum_{k} z_{i k}^{\prime} w_{k}^{\prime} \quad \forall i, k \\
& o_{i}^{x}-o_{j}^{x} \leq 0.5\left(w_{i}^{1}+w_{j}^{1}\right)+W\left(1-y_{i j}\right) \quad \forall i<j, \\
& o_{j}^{x}-o_{i}^{x} \leq 0.5\left(w_{i}^{1}+w_{j}^{1}\right)+W\left(1-y_{i j}\right) \quad \forall i<j, \\
& o_{i}^{\prime x}-o_{j}^{\prime x} \leq 0.5\left(w_{i}^{2}+w_{i}^{2}\right)+W\left(1-y_{i j}\right) \quad \forall i<j, \\
& o_{j}^{\prime x}-o_{i}^{\prime x} \leq 0.5\left(w_{i}^{2}+w_{i}^{2}\right)+W\left(1-y_{i j}\right) \quad \forall i<j, \\
& o_{i}^{y}-o_{j}^{y} \leq 0.5\left(l_{i}^{y}+l_{j}^{y}\right)+W\left(1-y_{i j}\right) \quad \forall i<j, \\
& o_{j}^{y}-o_{i}^{y} \leq 0.5\left(l_{i}^{y}+l_{j}^{y}\right)+W\left(1-y_{i j}\right) \quad \forall i<j, \\
& o_{i}^{\prime y}-o_{j}^{\prime y} \leq 0.5\left(l_{i}^{\prime y}+l_{j}^{\prime y}\right)+W\left(1-y_{i j}\right) \quad \forall i<j, \\
& o_{j}^{\prime y}-o_{i}^{\prime y} \leq 0.5\left(l_{i}^{\prime y}+l_{j}^{\prime y}\right)+W\left(1-y_{i j}\right) \quad \forall i<j, \\
& y_{i j} \leq G_{i}-G{ }_{j}+1 \quad \forall i<j,
\end{aligned}
$$

Constraints (34) and (44) determine which two departments can have common boundary.

$$
F_{1}=\sum_{j>i} \sum_{i} c_{i j} f_{i j}\left(\begin{array}{c}
\left(d_{i j}^{x}+d_{i j}^{y}\right) \\
+\left(d_{i j}^{\prime x}+d_{i j}^{\prime y}\right)
\end{array}\right)\left(G_{i} G_{j}+\left(1-G_{i}\right)\left(1-G_{j}\right)\right)
$$

Statement (45) calculates material handling cost if two 
departments are in the same floor.

$$
\begin{aligned}
& I=\left(1-s_{1}\right) s_{3}\left(\left(o_{i}^{x}+o_{i}^{y}\right)+\left(o_{i}^{\prime x}+o_{i}^{\prime y}\right)\right) \\
& \left.I I=\left(1-s_{1}\right)\left(1-s_{2}\right)\left(\left(\left(L-o_{i}^{y}\right)+o_{i}^{x}\right)+\left(\left(L-o_{i}^{\prime y}\right)+o_{i}^{\prime x}\right)\right)\right) \\
& \left.I I I=s_{1} s_{2}\left(\left(W-o_{i}^{x}\right)+o_{i}^{y}\right)+\left(\left(W-o_{i}^{\prime x}\right)+o_{i}^{\prime y}\right)\right) \\
& I V=s_{1}\left(1-s_{2}\right)\left(\left(\left(W-o_{i}^{x}\right)+\left(L-o_{i}^{y}\right)\right)+\left(\left(W-o_{i}^{\prime x}\right)+\left(L-o_{i}^{\prime y}\right)\right)\right) \\
& F_{2}=\sum_{j>i} \sum_{i} f_{i j}\left(\begin{array}{c}
c_{i j} H e+ \\
(I+I I+I I I+I V)
\end{array}\right)\left(G_{i}\left(1-G_{j}\right)+G_{j}\left(1-G_{i}\right)\right)
\end{aligned}
$$

(46) to (50) determine material handling cost between two departments if they are in different floors.

$$
\begin{aligned}
& U p_{i}^{x}=\left(o_{i}^{x}+o_{i}^{\prime x}\right)+0.5\left(w_{i}^{1}+w_{i}^{2}\right) \forall i, \\
& L o_{i}^{x}=\left(o_{i}^{x}+o_{i}^{\prime x}\right)-0.5\left(w_{i}^{1}+w_{i}^{2}\right) \forall i, \\
& U p_{i}^{y}=\left(o_{i}^{y}+o_{i}^{\prime y}\right)+0.5\left(l_{i}^{y}+l_{i}^{\prime y}\right) \forall i, \\
& L o_{i}^{y}=\left(o_{i}^{y}+o_{i}^{\prime y}\right)-0.5\left(l_{i}^{y}+l_{i}^{\prime y}\right) \forall i, \\
& F_{4}=\sum_{j>i} \sum_{i} a d j_{i j}\left(\begin{array}{c}
\left(\min \left\{U p_{i}^{x}, U p_{j}^{x}\right\}-\max \left\{L o_{i}^{x}, L o_{j}^{x}\right\}\right) \\
+\left(\min \left\{U p_{i}^{y}, U p_{j}^{y}\right\}-\max \left\{L o_{i}^{y}, L o_{j}^{y}\right\}\right)
\end{array}\right) \\
& \left(G G_{i}+\left(1-G_{i}\right)\left(1-G_{j}\right)\right)
\end{aligned}
$$

(51) to (55) calculate summation of closeness rating between departments.

$\operatorname{Min} Z=p_{1}\left(F_{1}+F_{2}+F_{3}\right)-p_{2} F_{4}$

$p_{1}+p_{2}=1, p_{1}, p_{2} \geq 0$

Objectives were formulated in a weighted form using (56) and (57)

$$
A=x . y ; x \geq 0, \quad y \in\{0,1\}
$$

$A \leq M y ; M$ is big number

$$
A \leq x+M(1-y)
$$

$$
A \geq x-M(1-y)
$$

Constraints (58) to (61) can afford to linearize product of variable by integer variable.

\section{GA and MA IMPLEMENTATION}

Evolutionary algorithms have been applied to many fields of optimization, and it has been observed that combination of evolutionary algorithms with problem-specific heuristics can lead to highly effective procedures. A memetic algorithm (MA) is a hybrid algorithm that augments a population-based search approach with a local search heuristic. MA is similar to genetic algorithm (GA). However, GA is based on biological evolution while MA imitates cultural evolution- in the sense that memes can be modified during an individual's lifetime whereas genes cannot. Thus, MAs are more likely to improve the quality of an individual. This approach proved to be highly efficient for this problem when large-sized test instances were used.

\section{Chromosome definition}

A flexible bay structure is used to place departments. The bay width is flexibly adjusted for departments assigned to the bay. However, the emphasis is on the location of the bay rather than on the arrangement of the departments. A chromosome is divided into three sections (Figure 1), two of which are composed of numbers that represent the departments for first floor and second one, and there is no explicit indication of the breakpoints between bays. However, the sequentially arranged departments can be grouped if they meet the conditions for forming a bay when the areas of the departments are added sequentially from left to right. If the summed area is in the range of the designated bay size and the length and width of the departments are within permissible intervals, then this set of departments can be grouped into a bay. Thus, a set of candidate breakpoints between each pair of bays can be determined. The third section of the chromosome represents binary variables $S_{1}, S_{2}$ and $S_{3}$ to determine the number and location of elevators. There can be one or two elevators. The mathematical model and the solution procedure are to determine the number of elevators after doing a trade-off between vertical material handling cost and elevator setup cost.

\section{Parent selection}

The same first individuals are uniformly randomly generated, and the selection of the parents for the next generation is done through tournament 3; consequently, the best individuals in the generation are more likely to move to the next generation. 


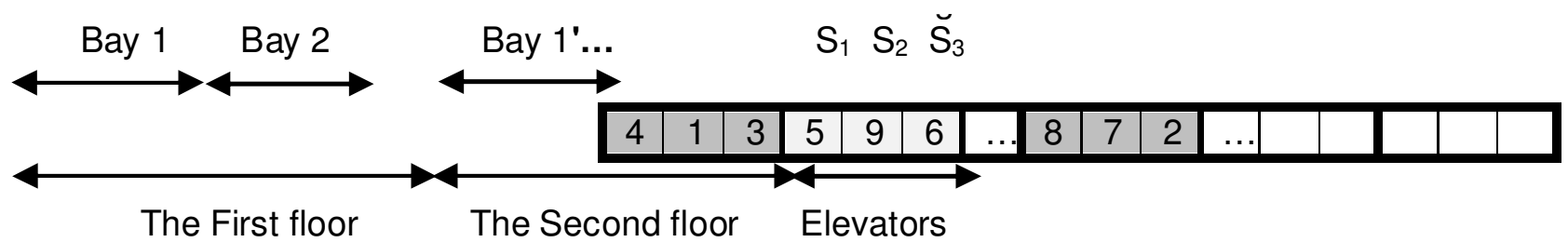

Figure 1. The designed chromosome.

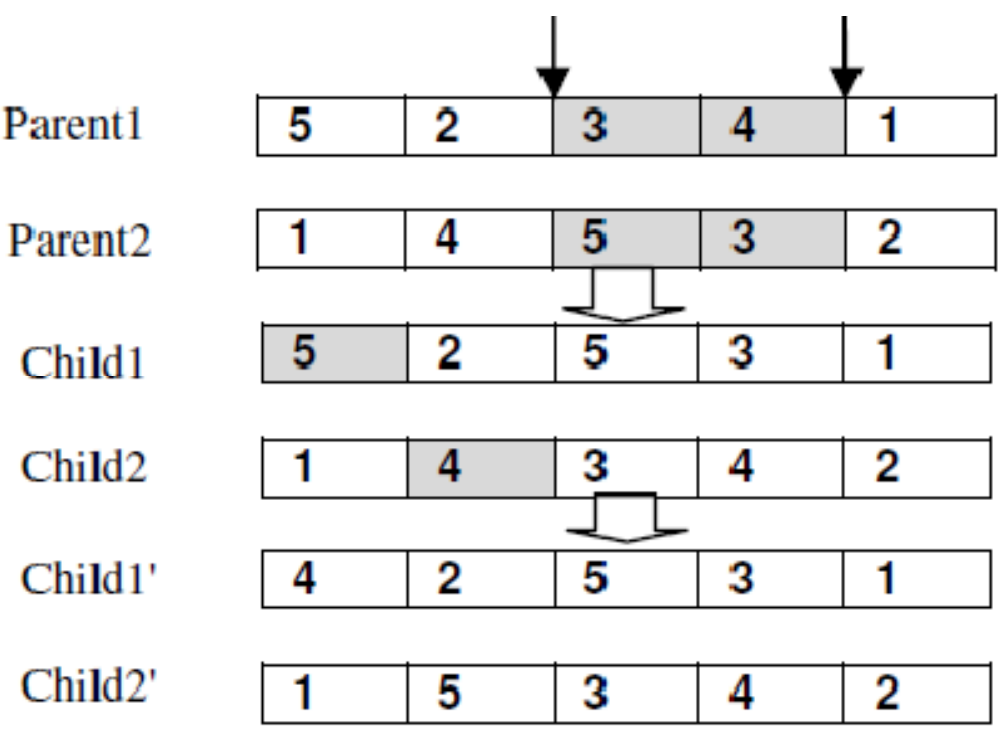

Figure 2. An example to illustrate crossover method.

\section{Crossover}

A modified partially matched crossover is used to prevent generation of infeasible solutions; since the partially matched crossover method exchanges genes within a parent, feasible offspring are obtained. The integer number in a chromosome, which displays the department, should not be duplicated after the process of crossover is finished since each number is unique within the chromosome. After exchange between the chromosomes, each chromosome is checked to see whether there are two of the same numbers in the new chromosomes. If there is a repeated number, then the repeated gene outside the crossed-over segment is selected and replaced with the first number from 1 to $n$, which is absent within the mentioned chromosome. This method is iterated until there is no repeated number. This method was easier to be coded and proved to perform crossover operation with less number of computations rather than partially matched crossover. Figure 2 shows an example of the crossover method. After exchanging genes between the two chromosomes in child 1, the first and third genes (number 5) are the same. So, the first gene which is outside the crossed-over segment must be replaced with
4 , as the first number from 1 to $n$ which does not already exist within child 1 . The same method is applied to child 2.

\section{Mutation}

A swap mutation operator is used for the mutation. Two uniformly randomly selected genes are swapped to generate a new chromosome. As mentioned with the crossover operator, the gene that represents each department is unique in the chromosome and should not be duplicated. The standard mutation operator chooses one of the genes in the chromosome and changes its value, but in this problem, the chromosome becomes an infeasible representation because the new gene would be either one of the integer numbers already in the chromosome or a number that does not stand for one of the departments.

\section{Local search}

A simple 2-opt algorithm, also known as a pairwiseinterchange heuristic, was used to enhance the GA to 
MA. The 2-opt algorithm considers only two departments at a time for exchange, and the algorithm discards the previous best solution whenever a better solution is found.

\section{Computational results}

The revolutionary algorithm was tested for different sizes. For small-sized test instances departments, the mathematical model yielded the optimal solution in reasonable time using Lingo 8:00. The algorithm obtained the optimal solution to some small-sized test instances. For largesized test instances, the combined SA and MA was compared with the combination of SA and corresponding GA and proved to yield better solutions but in more CPU runtime. The results proved that the designed algorithm is quite efficient in terms of runtime and quality of solutions.

\section{CONCLUSION}

In this paper, a multi-objective mixed integer linear programming model was developed to find the optimal solution to the multi-floor facility layout problem with unequal departmental areas in multi-bay environments where the bays are connected at one or two ends by an inter-bay material handling system. Also, a memetic algorithm was designed to solve large-sized test problems, and obtained optimal solution to some small-sized test instances. It proved to be highly efficient after a comparison with corresponding genetic algorithm for large-sized test instances and with the mixed integer formulation for small-sized test instances.

\section{REFERENCES}

Aiello G, Enea M, Galante G (2006). A multi-objective approach to facility layout problem by genetic search algorithm and Electre method. Robot. Comput. Integr. Manuf., 22: 447-455.

Arapoglu RA, Norman BA, Smith AE (2001). Locating Input and Output Points in Facilities Design-A Comparison of Constructive, Evolutionary, and Exact Methods, IEEE Trans. Evol. Comput., 5: 192203.

Bozer YA, Meller RD, Erlebacher SJ (1994). An Improvement-Type Layout Algorithm for Single and Multiple Floor Facilities. Manage. Sci., 40: 918-932.

Castillo I, Peters BA (2004). Integrating design and production planning considerations in multi-bay manufacturing facility layout. Eur. J. Oper. Res., 157: 671-687.

Chae J, Peters BA (2006). Layout Design of Multi-Bay Facilities with Limited Bay Flexibility. J. Manuf. Syst., 25: 1-11.

Chen CW, Sha DY (2005). Heuristic approach for solving the multiobjective facility layout problem. Int. J. Prod. Res., 43: 4493-4507.
Chen YK, Lin SW, Chou SY (2002)., An efficient two-staged approach for generating block layouts, Computers Oper. Res., 29: 489-504.

Drira A, Pierreval H, Hajri-Gabouj S (2007). Facility layout problems: A survey. Ann. Rev. Control, 31: 255-267.

Eklund NH, Embrechts MJ, Goetschalckx M (2006). An Efficient Chromosome Encoding and Problem-Specific Mutation Methods for the Flexible Bay Facility Layout Problem, IEEE Transactions on Systems, MAN, and Cybernetics-part C. Appl. Rev., 36: 109-113.

Enea M, Galante G, Panascia E (2005). The facility layout problem approached using a fuzzy model and a genetic search. J. Intell. Manuf., 16: 303-316.

Garey M R, Johnson D S (1979). Computers and intractability: A guide to the theory of NP-completeness, WH Freeman, New York, (1979).

Konak A, Coit DW, Smith AE (2006). "Multi-Objective Optimization Using Genetic Algorithms: A Tutorial," Reliab. Eng. Syst. Saf., 91: 992-1007.

Konak A, Kulturel-Konak S, Bryan AN, Smith AE (2006). A new mixed integer programming formulation for facility layout design using flexible bays. Oper. Res. Lett., 34: 660-672.

Kulturel-Konak S, Norman BA, Coit DW, Smith AE (2004). Exploiting Tabu Search Memory in Constrained Problems, INFORMS J. Comput., 16: 241-254.

Lee KY, Roh M, Jeong H (2005). An improved genetic algorithm for multi-floor facility layout problems having inner structure walls and passages. Comput. Oper. Res., 32: 879-899.

Loiola EM, de Abreu NMM, Boaventura-Netto PO, Hahn.P, Querido T (2007). Eur. J. Oper. Res., 176: 657-690.

Matsuzaki K, Irohara T, Yoshimoto K (1999). Heuristic algorithm to solve the multi-floor layout problem with the consideration of elevator utilization, Comput. Ind. Eng., 36: 487-502.

Meller RD, Bozer YA (1997). Alternative Approaches to Solve the MultiFloor Facility Layout Problem. J. Manuf. Syst.,16

Meller RD, Gau KY(1996). An Investigation of Facility Layout Objective Functions and Robust Layouts, Int. J. Prod. Res.,

Meller RD, Gau KY (1997). The Facility Layout Problem: Recent and Emerging Trends and Perspectives, J. Manuf. Syst., 15

Meller RD (1997). The multi-bay manufacturing facility layout problem, Int. J. Prod. Res., 35: 1229-1237.

Papageorgiou LG, Rotstein GE (1998). Continuous-domain mathematical models for optimal process layout, Ind. Eng. Chemistry Res., 37: 3631-3639.

Patsiatzis DI, Papageorgiou LG (2002). Optimal multi-floor process plant layout. Comput. Chem. Eng., 26: 575-583.

Peer SK, Sharma DK (2008). Human-computer interaction design with multi-goal facilities layout model. Comput. Math. Appl., 56: 21642174.

Peters BA, Yang T (1997). Integrated Facility Layout and Material Handling System Design in Semiconductor Fabrication Facilities. IEEE Trans. Semiconductor Manuf. 10: 1-1.

Pierreval H, Caux C, Paris JL, Viguier F(2003). Evolutionary approaches to the design and organization of manufacturing systems, Comput. Ind. Eng., 44: 339-364.

Şahin R, Türkbey O (2008). A simulated annealing algorithm to find approximate Pareto optimal solutions for the multi-objective facility layout problem. Int. J. Adv. Manuf. Technol., Vol. 37.

Tate DM, Smith AE (1995). Unequal-area facility layout by genetic search, IIE Trans., 27: 465-472.

Tompkins JA, Bozer YA, Tanchoco JMA, White JA, Tanchoco J ( 2003). Facilities Planning, Wiley, New York. 